OPEN ACCESS

Edited by:

Jianjun Wang,

Nanjing Institute of Geography and Limnology, Chinese Academy of

Sciences (CAS), China

Reviewed by:

Yuyi Yang,

Wuhan Botanical Garden, Chinese Academy of Sciences (CAS), China

Adrian Ochoa-Leyva,

National Autonomous University

of Mexico, Mexico

Shan Gong Wu,

Institute of Hydrobiology, Chinese Academy of Sciences (CAS), China

*Correspondence: Jinbo Xiong xiongjinbo@nbu.edu.cn

Specialty section: This article was submitted to

Systems Microbiology,

a section of the journal

Frontiers in Microbiology

Received: 03 August 2021 Accepted: 31 August 2021 Published: 08 October 2021

Citation:

Zhang W, Zhu Z, Chen J, Qiu Q and Xiong J (2021) Quantifying the Importance of Abiotic and Biotic Factors Governing the Succession of Gut Microbiota Over Shrimp

Ontogeny.

Front. Microbiol. 12:752750. doi: 10.3389/fmicb.2021.752750

\section{Quantifying the Importance of Abiotic and Biotic Factors Governing the Succession of Gut Microbiota Over Shrimp Ontogeny}

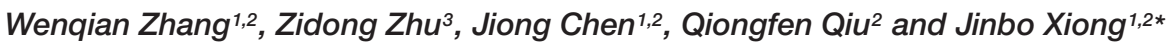 \\ ${ }^{1}$ State Key Laboratory for Managing Biotic and Chemical Threats to the Quality and Safety of Agro-Products, Ningbo \\ University, Ningbo, China, ${ }^{2}$ School of Marine Sciences, Ningbo University, Ningbo, China, ${ }^{3}$ School of Biochemical \\ Engineering, Jingzhou Institute of Technology, Jingzhou, China
}

Intensive studies have evaluated abiotic factors in shaping host gut microbiota. In contrast, little is known on how and to what extent abiotic (geochemical variables) and biotic (i.e., surrounding microbes, younger shrimp, and age) factors assemble the gut microbiota over shrimp ontogeny. Considering the functional importance of gut microbiota in improving host fitness, this knowledge is fundamental to sustain a desirable gut microbiota for a healthy aquaculture. Here, we characterized the successional rules of both the shrimp gut and rearing water bacterial communities over the entire shrimp farming. Both the gut and rearing water bacterial communities exhibited the time decay of similarity relationship, with significantly lower temporal turnover rate for the gut microbiota, which were primarily governed by shrimp age (days postlarval inoculation) and water $\mathrm{pH}$. Gut commensals were primary sourced (averaged 60.3\%) from their younger host, rather than surrounding bacterioplankton (19.1\%). A structural equation model revealed that water salinity, $\mathrm{pH}$, total phosphorus, and dissolve oxygen directly governed bacterioplankton communities but not for the gut microbiota. In addition, shrimp gut microbiota did not simply mirror the rearing bacterioplankton communities. The gut microbiota tended to be governed by variable selection over shrimp ontogeny, while the rearing bacterioplankton community was shaped by homogeneous selection. However, the determinism of rare and stochasticity of abundant subcommunities were consistent between shrimp gut and rearing water. These findings highlight the importance of independently interpreting host-associated and free-living communities, as well as their rare and abundant subcommunities for a comprehensive understanding of the ecological processes that govern microbial successions.

Keywords: shrimp gut microbiota, bacterioplankton community, temporal succession, SourceTracker, ecological processes, rare and abundant sub-communities 


\section{INTRODUCTION}

Litopenaeus vannamei is one of the most valuable shrimp species in aquaculture globally, while its production is being threatened by diverse diseases. It is now widely recognized that the gut microbiota contributes indispensable roles in sustaining host health (Xiong, 2018). For this reason, intensive studies have focused on factors shaping the gut microbiota, including life stage (i.e., larva, juvenile, or adult), disease (Lu et al., 2022), and surrounding environmental factors (Xiong et al., 2017; Hou et al., 2018). In contrast, we know little about how the biotic sources, e.g., younger host, affect the shrimp gut microbiota.

It is supposed that aquatic animals have a close association with their surrounding water microbiomes (De Schryver et al., 2014). However, survey studies show that the gut microbiota of shrimp is distinct from that in rearing water and/or sediment (Huang et al., 2018; Song et al., 2020). Our recent work evaluates to what extent rearing water and sediment bacterial communities affect the gut microbiota of shrimp, illustrating that shrimp acquire little of their gut commensals from rearing water (Xiong et al., 2019b). Instead, 66.7\% gut commensals of the adult shrimp are derived from their juveniles (Zhang et al., 2021). In accordance, ample evidence has shown that the structures of gut microbiota are differed significantly along shrimp life stages, which are distinct from those in the rearing water (Burns et al., 2016; Yan et al., 2016; Zhang et al., 2018). In this context, temporal changes in the shrimp gut microbiota are not parallel with those in rearing bacterioplankton. However, it seems that the gut microbiota of larval shrimp is more similar with the rearing bacterioplankton community, compared with the adults (Burns et al., 2016; Xiong et al., 2018). A possible explanation is that the selection on external taxa is increased as host matured (Xiong et al., 2019a; Xiao et al., 2021). However, the deteriorated water quality imposes stress on shrimp, which in turn depresses their capability of filtering on external taxa (Xiong et al., 2017). For example, nutrient accumulation in rearing water significantly alters shrimp gut microbiota at later farming stage (Lucas et al., 2010; Zhang et al., 2014; Xiong et al., 2016). Accordingly, there is non-linear trend in the relative importance of deterministicity in governing the gut microbiota over shrimp development (Xiong et al., 2019b). It is now recognized that the gut microbiota is conjointly affected by rearing geochemical variables, bacterioplankton, and host development (Xiong et al., 2019b; Xiao et al., 2021), while little is known on the interplay among these variables. Theoretical evidence has proposed that the successional pattern of host-associated (e.g., gut microbiota) communities is distinct from that of free-living bacteria (e.g., bacterioplankton) (Baselga, 2010; Xiong et al., 2019b), whereas experimental evidence is lacking. For these reasons, it remains unclear how and to what extent the gut microbiota is affected by rearing bacterioplankton community as shrimp aged, whereas this knowledge is fundamental for sustaining a health aquaculture.

A microbial community is comprised by a large number of rare species and a few highly abundant taxa (Brown et al., 2014). It is becoming clear that rare biosphere is functionally and ecologically important in a given community
(Lynch and Neufeld, 2015). For example, rare taxa serve a reservoir that can quickly respond to environmental changes, thereby promoting community stability in a wide variety of ecosystems (Shade et al., 2014). Additionally, rare subcommunity also contributes dispensable roles in nutrient cycling (Pester et al., 2010). Available studies have depicted that the freeing-living rare and abundant communities exhibit contrasting assembly processes (Mo et al., 2018). However, it remained uncertain whether the host-associated counterparts are ruled by the same ecological processes, as what has been observed for freeingliving community.

An ultimate goal of microbial ecology is to predict the responses of microbial communities to changing environments, yet this goal is difficult to achieve. One reason for this challenge is that there are two types of ecological processes, deterministicity and stochasticity, governing the microbial assembly (Van Der Gast et al., 2008). Deterministic processes include abiotic/biotic selection and biological interaction, while stochastic processes (also known as neutral processes) include dispersal-related processes and ecological drift (Venkataraman et al., 2015; Zhou and Ning, 2017). It has been perceived by ecologists that both deterministic and stochastic processes occur simultaneously in assembling local communities (Chase, 2010; Zhou et al., 2014), whereas no consensus has emerged regarding their relative importances. For a given community, if it is tailored by the dominance of deterministic processes, the temporally successional trend is predictable (Vanwonterghem et al., 2014). Intriguingly, it has been shown that the degrees of deviation in the gut microbiota from the successional trajectory as host aged are positively associated with the severity of the shrimp disease (Xiong et al., 2015). In this regard, it is essential to explore the underlying ecological processes governing the succession of gut microbiota over shrimp ontogeny.

Herein, we explored the successional rules of both the gut and the rearing water bacterial communities over the entire shrimp farming. The main purposes were (1) to evaluate the interplay among biotic (shrimp age), abiotic (water geochemical variables) factors, bacterioplankton community, and the shrimp gut microbiota; (2) to quantify the relative importances of external and internal sources to the gut microbiota over shrimp ontogeny; (3) to compare the underlying ecological processes governing the shrimp gut and rearing water bacterial communities, including total, abundant, and rare communities, by integrating multiple ecological approaches.

\section{MATERIALS AND METHODS}

\section{Experimental Design and Sample Collection}

Larval shrimp (L. vannamei) were introduced into 60 identical greenhouse ponds (concrete and rectangular, $30 \mathrm{~m} \times 60 \mathrm{~m}$, with a depth of $1.2 \mathrm{~m}$ ) on April 8, at Zhanqi, Ningbo, eastern China $\left(29^{\circ} 32^{\prime} \mathrm{N}, 121^{\circ} 31^{\prime} \mathrm{E}\right)$. One week later, both shrimp and rearing water samples were collected with an interval of 6-10 days from six selected ponds over the entire shrimp farming (from 15 April to 10 July). In order to remove 
microorganisms and suspended particles, rearing seawater was disinfected with sodium hypochlorite and alum and then aerated in open reservoirs for 3 weeks before usage. To reduce the spatial variability, water samples were collected from four representative points (similar locations in all ponds) and then pooled to compose one biological sample for a given pond. Water samples were stored in an icebox and were transported to laboratory for further processing. In total, we collected 144 samples $(6$ replicates $\times 12$ samplings $\times 2$ habitats $)$ for microbial community analysis.

Water temperature (WT), $\mathrm{pH}$, salinity (SAL), and dissolved oxygen (DO) were recorded in situ using corresponding probes (Oxi 340i; WTW, Weilheim, Germany) at a depth of $50 \mathrm{~cm}$ (below water surface). The concentrations of water total phosphorus (TP) and total nitrogen (TN) were analyzed following seawater analysis standard of China (AQSIQ, 2007).

\section{DNA Extraction, Amplification, and Sequencing}

To collect microbial cells, $0.5 \mathrm{~L}$ of water sample was prefiltered through nylon mesh (100 $\mu \mathrm{m}$ pore size) and subsequently filtered onto a $0.22-\mu \mathrm{m}$ membrane (Millipore, Boston, MA, United States) on the sampling day. To obtain high efficiency of DNA extracts, the pooled number of shrimp individuals was decided on the basis of their intestine size. Specifically, every three, two, or one intestine from larval, juvenile, or adult shrimp was pooled to compose one biological sample for each pond, respectively. The filters and shrimp intestines were placed into sterile tubes and were stored at $-80^{\circ} \mathrm{C}$.

Genomic DNA (gDNA) was extracted using a FastDNA Spin kit (MP Biomedicals, Carlsbad, CA, United States) following the manufacturer's protocols. The V3-V4 regions of bacterial 16S rRNA gene were amplified by primers: 341F $\left(5^{\prime}-\right.$ CCTAYGGGRBGCA-SCAG-3' $3^{\prime}$ and 806R $\left(5^{\prime}-\right.$ GGACTACNNGGGTATCTAA-3'). For each sample, triplicate $50 \mu \mathrm{l}$ PCRs were performed which contained $25 \mathrm{ng}$ DNA extracts as template with the following conditions: 25 cycles of denaturation at $95^{\circ} \mathrm{C}$ for $30 \mathrm{~s}$, annealing at $55^{\circ} \mathrm{C}$ for $30 \mathrm{~s}$, and extension at $72^{\circ} \mathrm{C}$ for $45 \mathrm{~s}$, with a condition of $72^{\circ} \mathrm{C}$ for $10 \mathrm{~min}$ for the final elongation step. The triplicate amplicons for each sample were pooled and purified using a PCR fragment purification kit. Equimolar amounts of amplicons from each sample were pooled and then were sequenced in a single run using the Illumina MiSeq platform (Illumina, San Diego, CA, United States), resulting in $2 \times 300$ bp paired-end reads.

\section{Processing of Illumina Sequencing Data}

The paired-end reads were joined and assigned to samples based on barcode. The merged sequences were analyzed using the QIIME2 pipeline (Caporaso et al., 2010). Specifically, sequences at $<200$ bp in length, showed ambiguous bases, or had a mean quality score $<20$ were filtered. Then, sequences were binned into operational taxonomic unit (OTU) with 97\% cutoff using UCLUST (Edgar, 2010). The most abundant sequence from each OTU was selected as representative and then was taxonomically assigned a closed reference (Greengenes Database, release 13.8)
(DeSantis et al., 2006), which enables each identified OTU to have a close relative. After the taxonomy had been assigned, Archaea, Chloroplast, unclassified Bacteria, as well as singletons, were excluded from subsequent analysis.

\section{Statistical Analysis}

We defined OTUs with a mean relative abundance of $\geq 0.01 \%$ across the samples as "abundant" OTUs, whereas OTUs with a mean relative abundance of $<0.001 \%$ as "rare" OTUs follow the criterion as described elsewhere (Logares et al., 2014; Liu et al., 2015).

All statistical analyses were performed in the R-environment ${ }^{1}$ unless otherwise indicated. To improve normality and homoscedasticity, bacterial communities were Hellinger transformed, while environmental variables were normalized by using function decostand in package vegan. Heatmap was used to depict the abundance of the top 20 dominant bacterial genera in the shrimp gut microbiota and those in the bacterioplankton communities. Paired $t$-test (pond served a conditional factor) was used to evaluate the significance ( $p<0.05$ level) of diversity between gut and corresponding water bacterial communities at each sampling. A non-metric multidimensional scaling (NMDS) analysis was used to compare the differences in the structures of rearing water and shrimp gut bacterial communities based on Bray-Curtis distance. The significance between groups was tested using an analysis of similarity (ANOSIM) (Anderson, 2010). Permutational multivariate analysis of variance (perMANOVA) was conducted to quantify the relative contributions of habitat (gut or water), shrimp age (days postinoculation), and their interaction to the variations in bacterial community using the “adonis" function (Anderson, 2010).

The time decay of similarity relationship was used to compare the temporal turnover rate (the slope of the regression) between the gut and water bacterial communities over shrimp farming (Xiong et al., 2014). To account for zero similarity values, bacterial community similarity and lag of shrimp age were In transformed (Talbot et al., 2014). Here, we treated pond as a conditional factor, thereby enabling us to compare the significance (paired $t$-test) in turnover rate between gut and rearing water communities. The multiple regression on distance matrices (MRM) was further used to determine variables that triggered the temporal turnover of bacterial communities. This approach offers advantages over the traditional partial Mantel test to investigate linear, non-linear or non-parametric relationships between a multivariate response distance matrix and any number of explanatory distance matrices (Legendre et al., 1994; Lichstein, 2007). To minimize the collinearity between environmental factors, we used variable clustering to assess the redundancy of variables by the "VARCLUS" procedure in package Hmisc before applying MRM. Then, a matrix randomization procedure with standardized predictor variables was implemented using package ecodist (Goslee and Urban, 2007). To reduce the effect of spurious relationships between variables, we ran the MRM test twice, after removal of insignificant variables by the first run. The results were reported from the second run. A structural equation

\footnotetext{
${ }^{1}$ http://www.r-project.org
} 
model (SEM) was used to uncover the interplay among rearing water geochemical variables, bacterioplankton and gut bacterial communities, and shrimp age in AMOS 23.0 (IBM, Chicago, IL, United States) (Byrne, 2001).

SourceTracker analysis was employed to quantify the relative contributions of both external (rearing water bacterioplankton community) and internal (the gut microbiota of adjacent younger shrimp) resources to the shrimp gut microbiota (Knights et al., 2011). This approach analyzed the relative abundance of each OTU share in water or younger shrimp gut with older ones, to calculate the probability that each OTU detected in the shrimp gut was sourced from the rearing water or adjacent younger shrimp.

To evaluate the phylogenetic community assembly, the "standardized effect size" of phylogenetic community structure (ses.MNTD) was calculated for non-random phylogenetic relatedness (MNTD) by the difference between phylogenetic distances in the observed communities vs. null communities generated with 999 randomizations, divided by the standard deviation of phylogenetic distances in the distribution using the Picante package (Kembel et al., 2010; R Core Team, 2013). For a given community, ses.MNTD value less than -2 indicates that the community is more phylogenetically related than expected by chance (determinism), whereas ses.MNTD value greater than +2 indicates that a community is less closely related than expected by chance (stochasticity) (Webb et al., 2002; Stegen et al., 2012). Pairwise phylogenetic turnover between communities was calculated as the MNTD metric ( $\beta M N T D)$ using the "comdistnt" function (abundance.weighted = TRUE) in package picante (Kembel et al., 2010). The community assembly processes were further evaluated by $\beta$ NTI using the "ses.mntd" function (Kembel et al., 2010) and a null modeling approach (Stegen et al., 2012), respectively. $\beta$ NTI (the difference between the calculated $\beta$ MNTD and the null-model estimation) values were quantified by either accounting for $\beta$ NTI is the number of standard deviations that the observed $\beta$ MNTD is from the mean of the null distribution. A value of $\beta$ NTI of $>2$ or $<-2$ indicates greater than or less than the expected phylogenetic turnover, respectively (Stegen et al., 2012).

\section{RESULTS}

\section{Temporal Successions of Shrimp Gut and Rearing Water Bacterial Communities}

In total, 3,842,244 high-quality sequences, with 17,38536,579 sequences per sample (mean \pm standard deviation, $26,868 \pm 4,620$ ) were collected across the enrolled 143 samples. After rarefaction, we obtained 32,811 OTUs in the analysis. Diversity of the gut microbiota was temporally stable over shrimp ontogeny, whereas bacterioplankton diversity linearly increased over the same timeframe, as supported by both Shannon and phylogenetic diversity indices (Supplementary Figure 1). The NMDS biplot depicted that the gut microbiota were distinct from bacterioplankton communities (Figure 1). There were sequential successions of both the gut microbiota
A

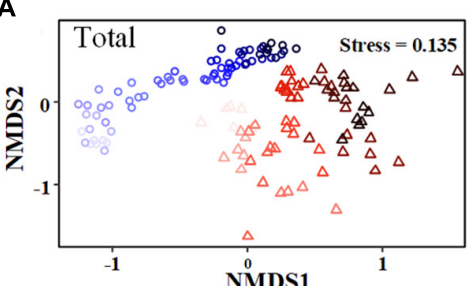

B

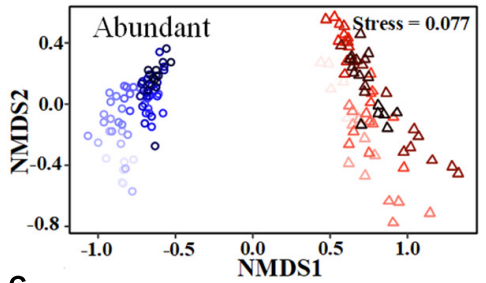

C

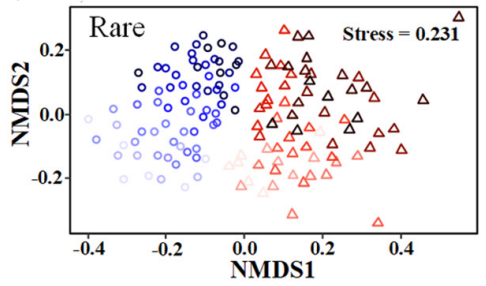

D

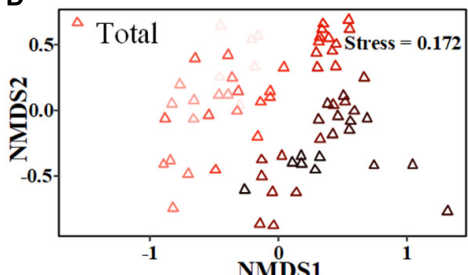

E
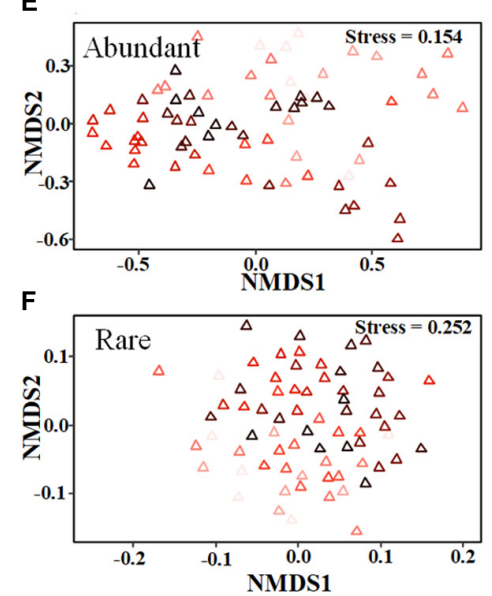
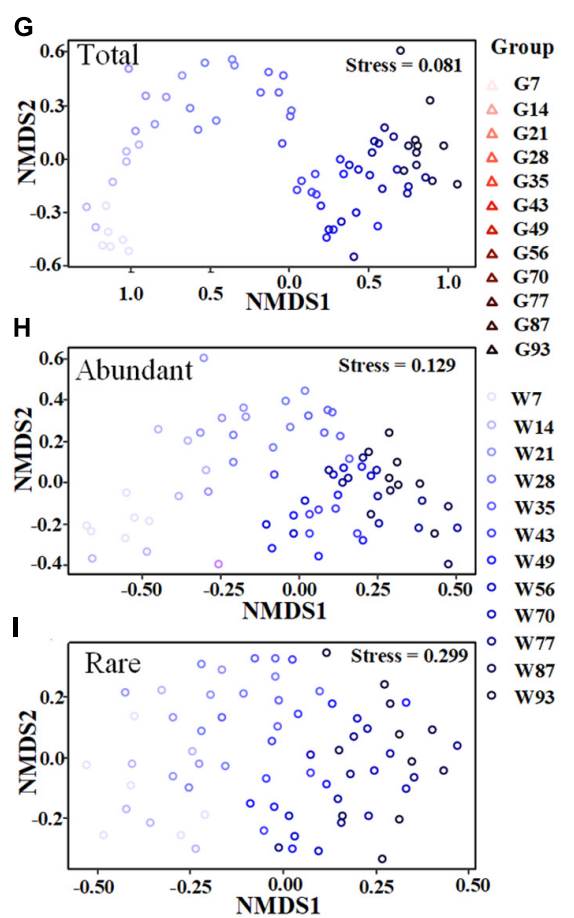

FIGURE 1 | Non-metric multidimensional scaling (NMDS) ordinations showing the structures of total, abundant and rare communities. NMDS ordination of the total, abundant, and rare bacterial communities in both the shrimp gut and rearing water (A-C), shrimp gut (D-F), rearing water (G-I) based on Bray-Curtis similarity, respectively. Samples were coded and colored by habitat and shrimp life stage, of which $\mathrm{G}$ and $\mathrm{W}$ indicate shrimp gut and water, respectively. 
and bacterioplankton communities during shrimp farming, as evidenced by increased distances along NMDS axis 1 (Figure 1). These differences were confirmed by the ANOSIM, illustrating that shrimp gut bacterial communities were significantly distinct between every paired age (Supplementary Table 1). In contrast, there were no significant differences between some adjacent pairs of bacterioplankton communities, e.g., W28 vs. W21, W56 vs. W49, W77 vs. W70, and W93 vs. W87 (Supplementary Table 2). Furthermore, perMANOVA revealed that both habitat (shrimp gut or rearing water) and shrimp age significantly $(p<0.001$ in both cases) contributed to the variations in bacterial community. Shrimp age exerted consistently higher importances than habitat in governing the total, abundant, and rare bacterial communities (Table 1). Both the gut microbiotas and bacterioplankton communities exhibited significant time decay of similarity relationship. The temporal turnover rate of bacterial community in shrimp gut $(-0.290 \pm 0.127)$ was significantly (paired $t$-test, $p=0.001)$ lower than that in rearing water $(-0.827 \pm 0.083)$ (Figure 2). MRM revealed that the temporal succession was primarily governed by shrimp age, water temperature, and $\mathrm{pH}$ (Table 2). Notably, each of the three variables exerted higher contributions in governing the bacterioplankton communities compared with the gut microbiota (Table 2), suggesting that bacterioplankton communities were more strongly affected by environmental factors. The MRM model explained $66 \%$ $(p<0.001)$ variation in bacterioplankton community, while only $21 \%(p<0.001)$ in the gut microbiota. Additionally, shrimp age contributed larger partial regression coefficients in shaping abundant subcommunities than corresponding rare counterparts in both the gut and rearing water.

\section{Factors Governing the Temporal Successions of Bacterial Community}

A forward selection procedure identified four water variables (TP, DO, $\mathrm{pH}$, salinity) and shrimp age that significantly contributed to the variations in bacterial community $(p<0.01)$ (Supplementary Figure 2 and Supplementary Table 3). The four water variables were significantly associated with shrimp age, which were attributed to the temporal dynamics of water variables during shrimp farming. Bacterioplankton community was positively correlated with salinity $(\lambda=0.28, p=0.007)$, $\mathrm{pH}(\lambda=0.23, p=0.002)$, and DO $(\lambda=0.14, p=0.048)$, and

TABLE 1 | Quantitative effects of sampling time and habitats on variation in community composition using non-parametric permutational multivariate analysis of variance (perMANOVA) with adonis function.

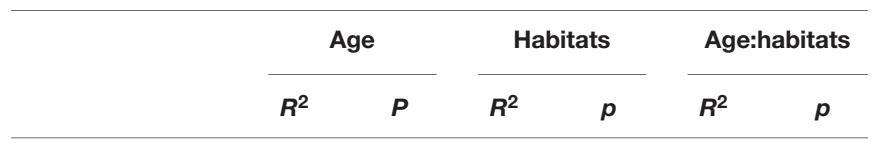

Community structure

$\begin{array}{lllllll}\text { Total } & 0.306 & <0.001 & 0.150 & <0.001 & 0.431 & <0.001 \\ \text { Rare } & 0.116 & <0.001 & 0.022 & <0.001 & 0.138 & <0.001 \\ \text { Abundant } & 0.315 & <0.001 & 0.167 & <0.001 & 0.455 & <0.001\end{array}$

The $R^{2}$ values represent the proportion of the community variation constrained by each variable or their interaction.

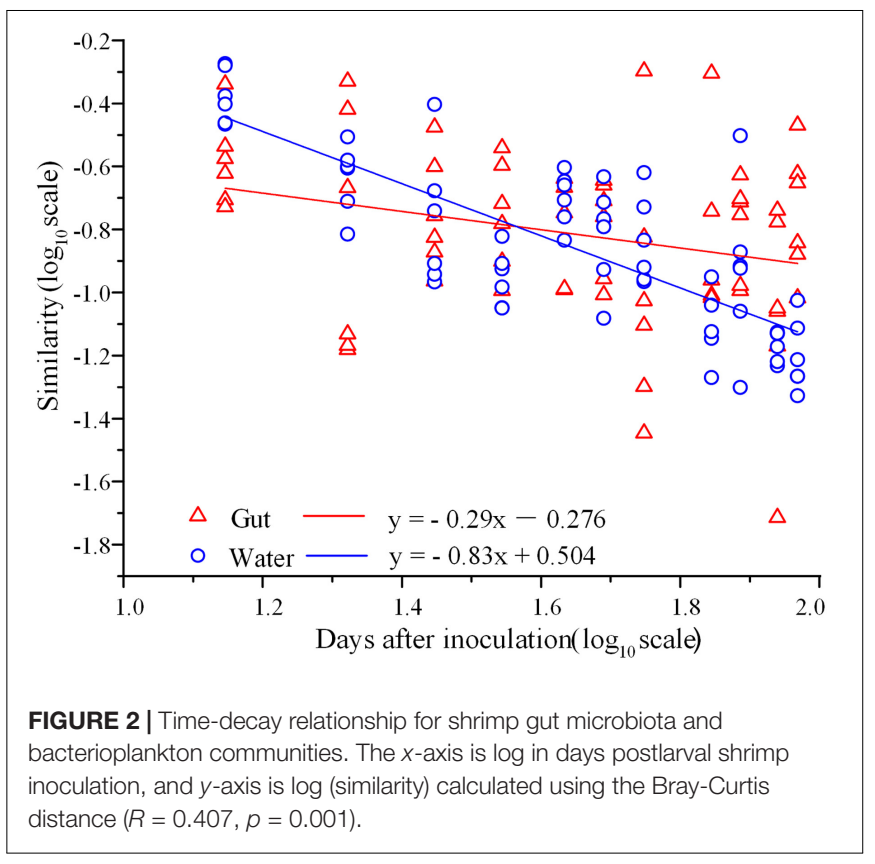

was negatively affected by TP $(\lambda=-0.34, p<0.001)$ (Figure 3 and Supplementary Table 3). Shrimp age was significantly associated with bacterioplankton community (0.50). The gut microbiota was affected by the combination of direct $(0.34)$ and weak indirect (0.09) effects of shrimp age (Figure 3 and Supplementary Table 3). Notably, bacterioplankton community contributed a weak and insignificant direct effect on the assembly of shrimp gut microbiota. As expected, abundant and rare subcommunities exhibited significant and positive contributions to corresponding total bacterial communities, with much higher contributions of the abundant subcommunities (Figure 3 and Supplementary Table 3).

\section{Sources of Shrimp Gut Commensals Over Shrimp Ontogeny}

The relative proportion of shared OTUs between shrimp gut and rearing water was negligible, ranged from 0.26 to $2.11 \%$ (Supplementary Figure 3 ). Thus, the rearing water bacterioplankton community contributed minor role in affecting the shrimp gut microbiota. To test whether gut microbiota parallelly changed with rearing water bacterial communities along shrimp farming, temporal dynamics of the top 20 dominant bacterial genera in the shrimp gut were compared with those in the rearing water (Figure 4). The relative abundances of Vibrio, Salinivibrio, and Haloferula genera were abundant in shrimp gut but were rare in rearing water. Only six dominant bacterial genera in shrimp gut, such as Ruegeria, Marivita, and Flavobacterium, were positively correlated with these in bacterioplankton communities, but not for the other 12 genera, including Vibrio and Pseudoalteromonas (Figure 4A). A similar pattern was observed for the most rare 20 bacterial genera in the shrimp gut, in which only genera of Sedimentibacter, Cupriavidus, and Marinobacterium were significantly associated with these 
TABLE 2 | Results of the multiple regression on distance matrices (MRM) for shrimp gut, bacterioplankton, and their abundant and rare communities.

\begin{tabular}{|c|c|c|c|c|c|c|c|c|c|c|c|c|}
\hline \multirow[t]{2}{*}{ Habitat } & \multicolumn{6}{|c|}{ Gut } & \multicolumn{6}{|c|}{ Rearing water } \\
\hline & \multicolumn{2}{|c|}{ Total } & \multicolumn{2}{|c|}{ Rare } & \multicolumn{2}{|c|}{ Abundant } & \multicolumn{2}{|c|}{ Total } & \multicolumn{2}{|c|}{ Rare } & \multicolumn{2}{|c|}{ Abundant } \\
\hline Age & 0.181 & $<0.001$ & 0.007 & 0.001 & 0.118 & $<0.001$ & 0.421 & $<0.001$ & 0.229 & $<0.001$ & 0.541 & $<0.001$ \\
\hline WT & 0.093 & 0.01 & ND & ND & 0.089 & $<0.001$ & 0.301 & $<0.001$ & ND & ND & 0.299 & $<0.001$ \\
\hline BOD & NS & NS & ND & ND & ND & ND & 0.216 & 0.002 & ND & ND & 0.216 & $<0.001$ \\
\hline DO & ND & ND & ND & ND & ND & ND & 0.258 & $<0.001$ & 0.13 & $<0.001$ & 0.256 & $<0.001$ \\
\hline TP & ND & ND & 0.014 & $<0.001$ & ND & ND & ND & ND & 0.076 & $<0.001$ & ND & ND \\
\hline TN & ND & ND & 0.001 & NS & ND & ND & 0.254 & $<0.001$ & ND & ND & ND & ND \\
\hline
\end{tabular}

ND, not determined (removed by the VARCLUS results); NS, not significant.

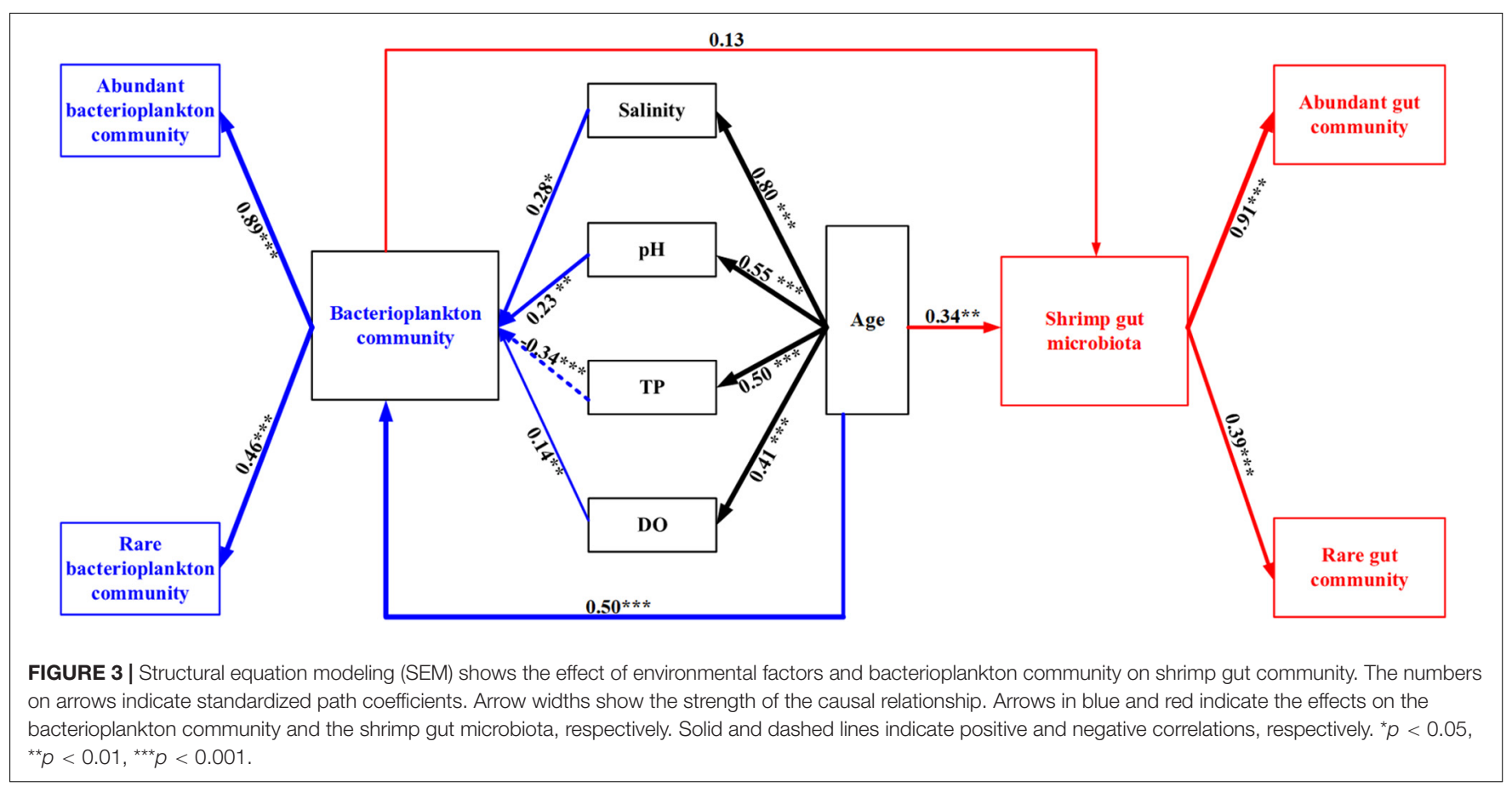

in rearing water (Figure 4B). Overall, the compositions and abundances of the bacteria in gut were insignificantly affected by the rearing bacterioplankton community over shrimp ontogeny.

SourceTracker analysis was used to quantify the relative contribution of external sources (rearing water) on the shrimp gut microbiota at each sampling (Figure 5A). In general, larval shrimp (breeding days less than 35 ) sourced little commensals from rearing water compared with juveniles and adults, with the exception on day 56. Bacterioplankton community contributed $43.3 \%$ (averaged contribution) of the species to shrimp gut microbiota, whereas most of the source was unknown (Figure 5A). When integrating the adjacent younger shrimp as an internal source for the gut microbiota in the model, the relative contribution of rearing water to gut microbiota sharply decreased to $19.1 \%$ (averaged proportion, ranged from 1.22 to $54.7 \%)$. Instead, gut commensals were primarily derived from the adjacent younger shrimp, with an averaged contribution of $60.3 \%$. Accordingly, the proportion of unknown source of gut microbiota sharply decreased to $20.5 \%$ (Figure 5B). Taken together, the majority of gut commensals sourced little species from surrounding species pool, which were temporally sustained over shrimp ontogeny.

\section{Ecological Processes Govern the Successions of Bacterial Community}

The ses.MNTD values of gut and rearing water bacterial communities were significantly lower than zero, suggesting that the two communities tended to be phylogenetically clustering (Supplementary Figure 4). Additionally, most of the $\beta$ NTI values of gut microbiotas and bacterioplankton communities were less than -2 , indicating that the dominant role of deterministic processes assembled the gut microbiota and bacterioplankton 
A

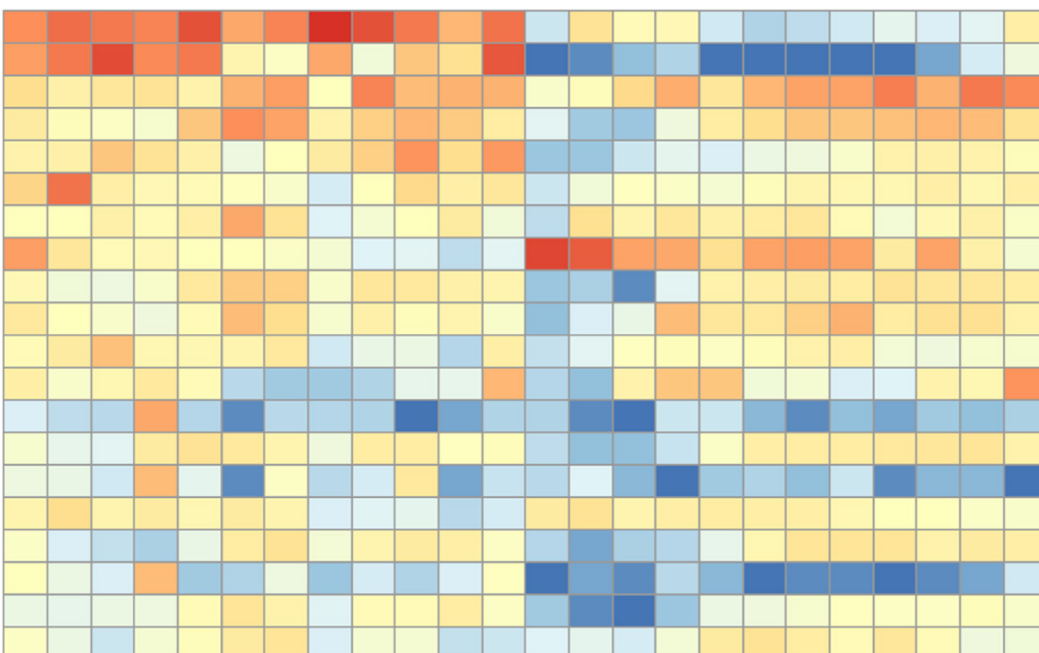

G7 G14 G21 G28 G35 G43 G49 G56 G70 G77 G87 G93 W7 W14W21W28W35W43W49W56W70W77W87W93

B

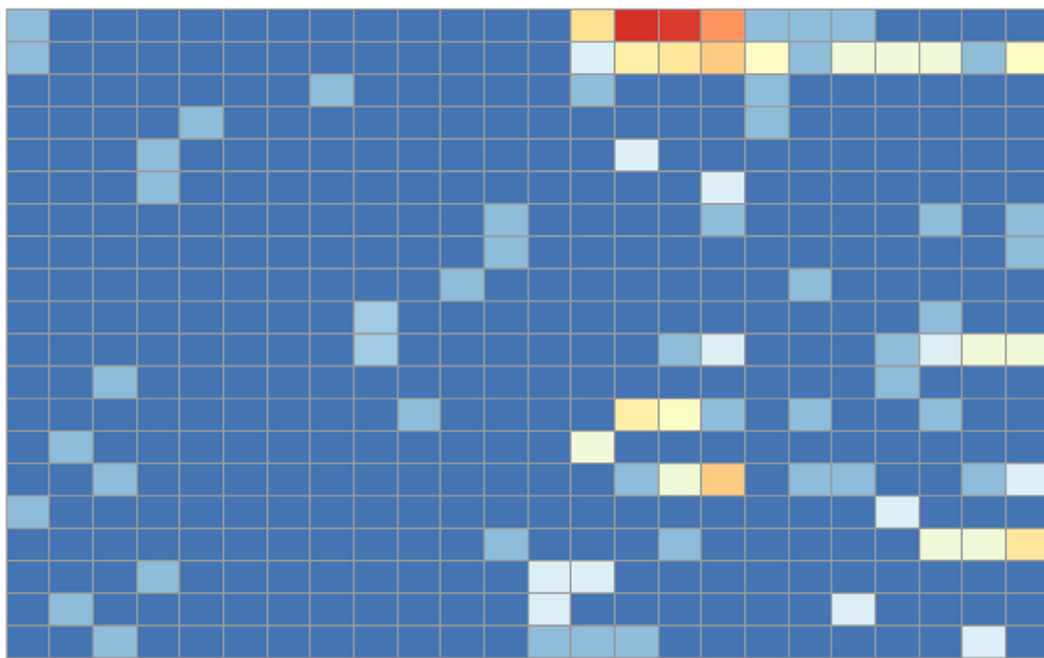

Vibrio

Salinivibrio

Planctomyces

Haloferula

Photobacterium

Pseudoalteromonas

Verrucomicrobium

Marivita

Robiginitalea

Luteolibacter

Tenacibaculum

Flavobacterium

Bacillus

Demequina

Sphingomonas

Dinoroseobacter

Octadecabacter

Bacteroides

Rubritalea

Ruegeria

$\begin{array}{lcc} & \mathbf{R} & \boldsymbol{P} \\ \text { Agrococcus } & -0.191 & 0.551 \\ \text { Leucobacter } & -0.407 & 0.189 \\ \text { Friedmanniella } & -0.135 & 0.676 \\ \text { Xylanimicrobium } & -0.091 & 0.779 \\ \text { SC3-56 } & -0.091 & 0.779 \\ \text { Bizionia } & -0.091 & 0.779 \\ \text { Acidaminococcus } & 0.522 & 0.082 \\ \text { Sedimentibacter } & \mathbf{1 . 0 0 0} & <\mathbf{0 . 0 0 1} \\ \text { Caulobacter } & -0.091 & 0.779 \\ \text { Aurantimonas } & -0.091 & 0.779 \\ \text { Hyphomicrobium } & 0.000 & 1.000 \\ \text { Roseobacter } & -0.091 & 0.779 \\ \text { Thalassobius } & -0.014 & 0.967 \\ \text { Cupriavidus } & \mathbf{1 . 0 0 0} & <\mathbf{0 . 0 0 1} \\ \text { Deefgea } & -0.065 & 0.840 \\ \text { Cellvibrio } & -0.091 & 0.779 \\ \text { Marinobacterium } & \mathbf{- 0 . 8 4 8} & <\mathbf{0 . 0 0 1} \\ \text { Steroidobacter } & -0.135 & 0.676 \\ \text { Pseudoxanthomonas } & -0.135 & 0.676 \\ \text { Prosthecobacter } & 0.275 & 0.387\end{array}$

G7 G14 G21 G28 G35 G43 G49 G56 G70 G77 G87 G93 W7 W14W21W28W35W43W49W56W70W77W87W93

$\begin{array}{ccc}\mathbf{R} & \boldsymbol{P} & \begin{array}{c}\text { Relative } \\ \text { abundance }\end{array} \\ -0.128 & 0.691 & \\ 0.446 & 0.146 & \\ \mathbf{0 . 6 8 0} & \mathbf{0 . 0 1 5} & \mathbf{1 5} \\ 0.343 & 0.275 & \\ \mathbf{0 . 6 1 6} & \mathbf{0 . 0 3 3} & \\ -0.343 & 0.275 & \\ 0.208 & 0.517 & \mathbf{1 0} \\ \mathbf{0 . 8 8 8} & <\mathbf{0 . 0 0 1} & \\ 0.417 & 0.177 & \\ -0.117 & 0.717 & \\ 0.025 & 0.939 & \mathbf{5} \\ \mathbf{0 . 9 4 6} & <\mathbf{0 . 0 0 1} & \\ \mathbf{0 . 5 7 7} & \mathbf{0 . 0 4 9} & \\ 0.098 & 0.762 & \\ -0.300 & 0.343 & \\ \mathbf{0 . 9 1 2} & <\mathbf{0 . 0 0 1} & \\ \mathbf{0 . 5 7 9} & \mathbf{0 . 0 4 8} & \\ 0.410 & 0.185 & \\ 0.340 & 0.280 & \\ \mathbf{0 . 6 4 9} & \mathbf{0 . 0 2 2} & \end{array}$

51

.189

0.676

.779

0.779

.779

0.001

.779

1.000

.779

.001

840

.676

0.387

FIGURE 4 | The relative abundances of the top abundant 20 bacterial genera (A) and the most rare 20 bacterial genera (B) in the gut and those in bacterioplankton communities. Pearson's correlations and the significances of the genera between shrimp gut and rearing water are shown on the right.

community (Supplementary Figure 5). To evaluate the trends of ecological processes over shrimp ontogeny, $\beta$ NTI values were regressed against the lag of shrimp age. The temporal trends of $\beta$ NTI were different between shrimp gut and rearing water bacterial communities (Figure 6). Specifically, there was a significant and positive correlation $(R=0.16, p=0.034)$ between $\beta$ NTI values of the total gut microbiota as shrimp aged (Figure 6A), whereas those of total bacterioplankton community exhibited the opposing trend $(R=-0.22, p=0.003)$ (Figure 6B). There were no significant correlations between $\beta$ NTI values of the abundant subcommunities in gut or rearing water during shrimp farming. In addition, most of the $\beta$ NTI values of abundant subcommunity were between -2 and 2 , indicating the dominant role of stochastic processes in assembling abundant subcommunity (Figures 6C,D). In contrast, the $\beta$ NTI values of rare subcommunities in both the gut $(R=-0.25, p=0.001)$ and rearing water $(R=-0.61, p<0.001)$ significantly decreased over the same timeframe, which tended to be less than -2 (Figures 6E,F).

\section{DISCUSSION}

Despite recent progress, little is known about the underlying ecological processes governing the successional patterns of host-associated microbes, especially their abundant and rare counterparts. To address this pressing knowledge gap, we explored how and to what extent abiotic (water geochemical variables) and biotic (i.e., younger shrimp, host age, and rearing bacterioplankton community) factors affected the gut microbiota over shrimp ontogeny. In addition, we quantified the relative contributions of external (rearing water) and internal 

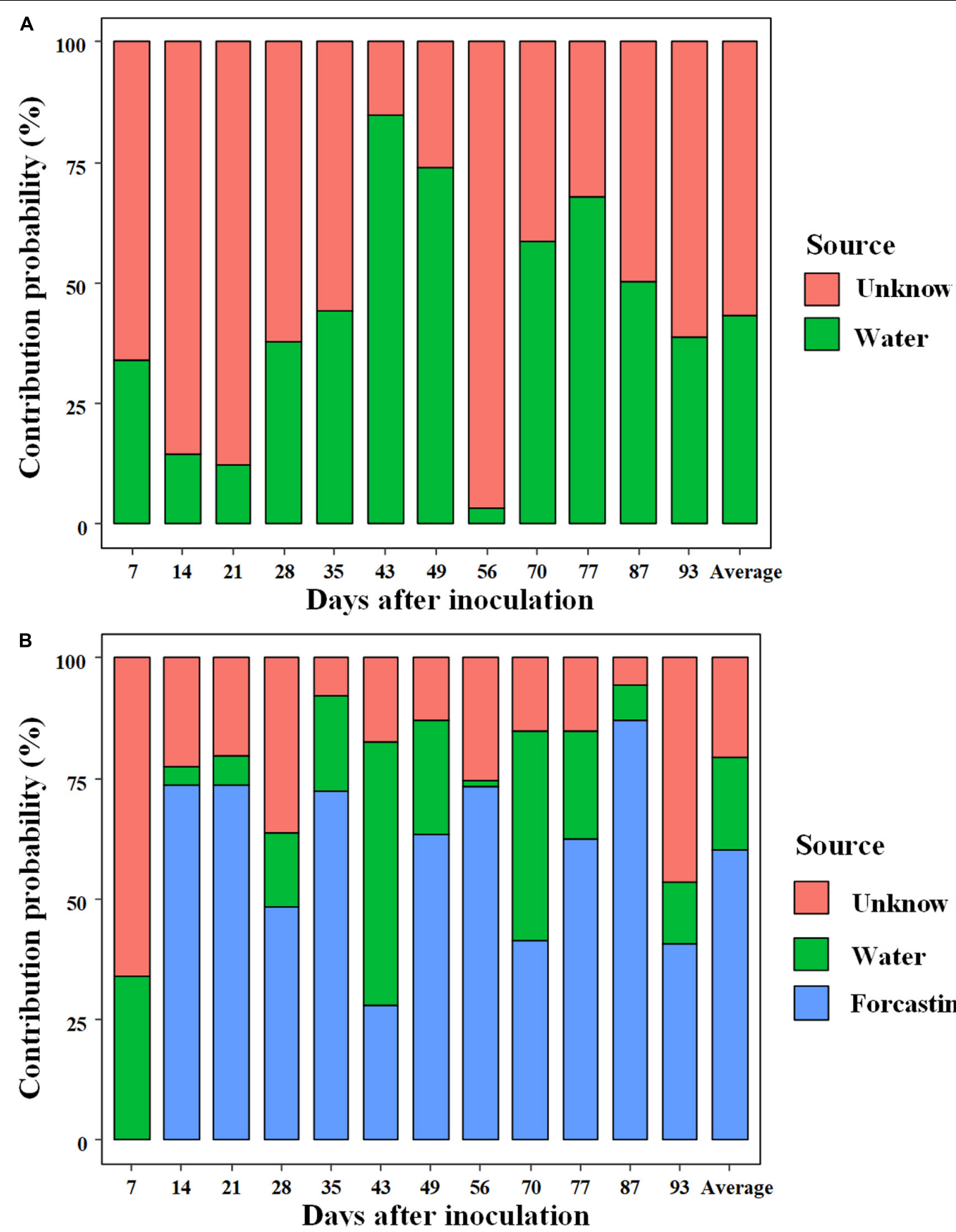

Source

Unknow

Water

Forcasting

FIGURE $\mathbf{5}$ | SourceTracker analyzes the relative contribution of external (rearing water) (A) and internal (gut commensals of the adjacent younger shrimp) sources (B) to the shrimp gut commensals.

(adjacent younger shrimp gut microbiota) sources on the shrimp gut commensals. These findings yield novel insights into the assembly of gut microbiota over shrimp ontogeny from an ecological perspective. It is worthy to note that we used OTU clustering methods instead of the more recently developed amplicon sequence variants (ASVs). However, it has been shown that all $\alpha$ and $\beta$ diversity metrics are highly positively correlated $(r>0.90)$ between samples analyzed with either ESVs or traditional OTUs. ESV or OTU methods often reveal similar ecological results, with indistinguishable statistical inferences (Glassman and Martiny, 2018). Similarly, a recent study depicts that OTUs and ASVs produce comparable shrimp microbiota (García-López et al., 2021). Thus, standard microbial community analyses are not overly sensitive to the particulars of binning approaches (Glassman and Martiny, 2018). In addition, we used a closed reference for taxonomical assignment, which has excluded spurious taxa. For these reasons, our findings are not biased by OTU clustering methods. 

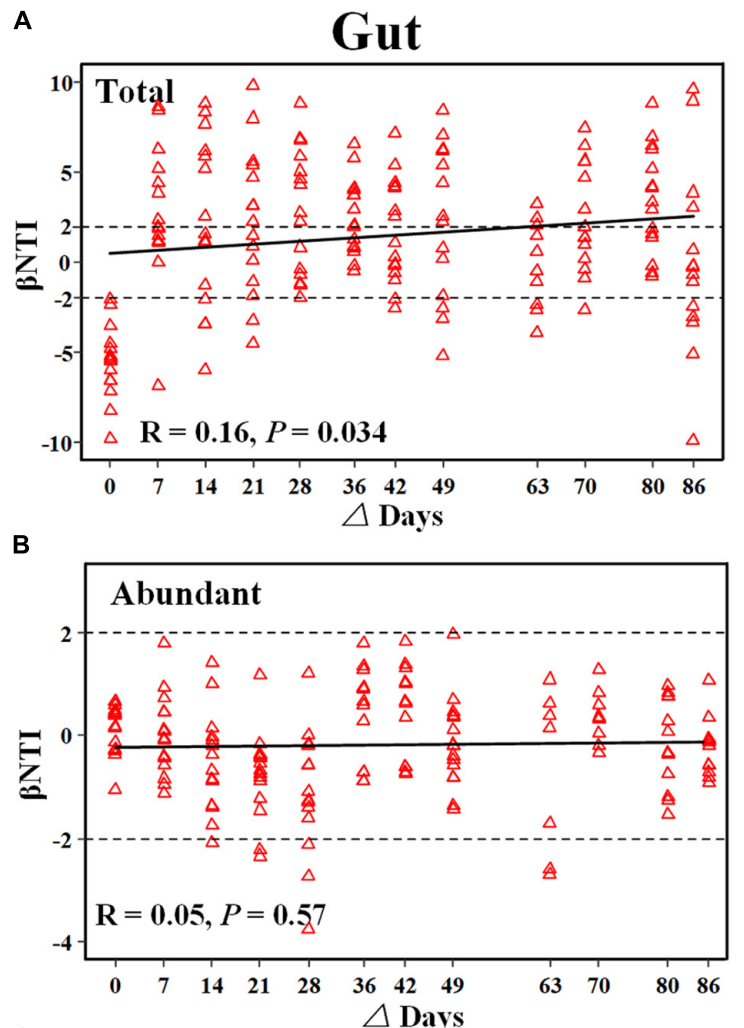

C

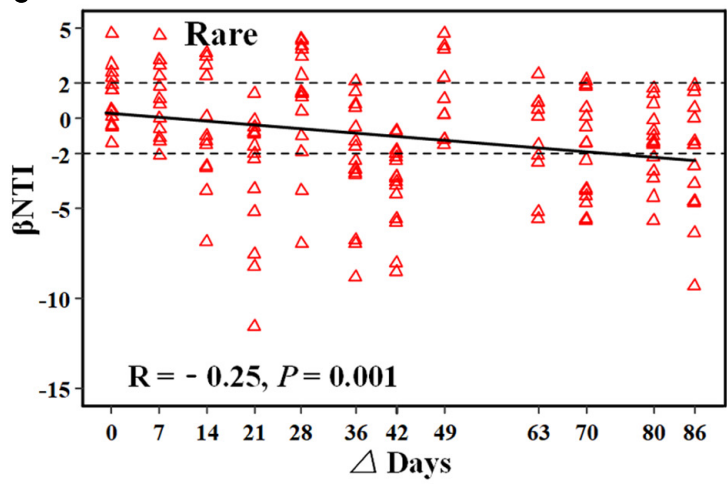

D
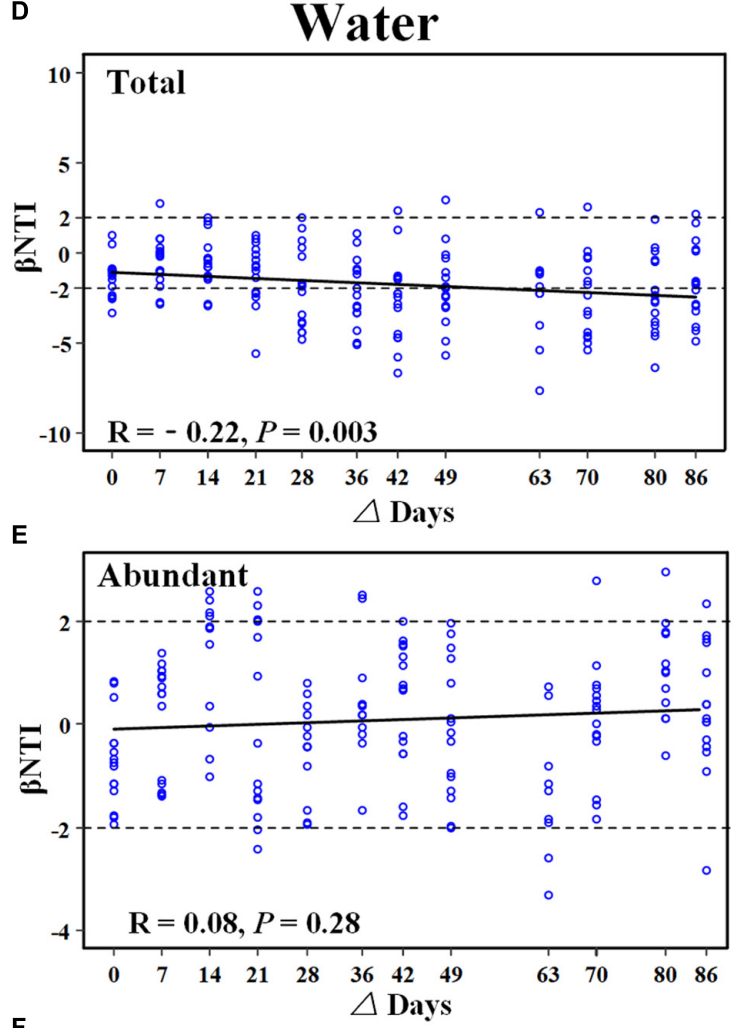

$\mathbf{F}$

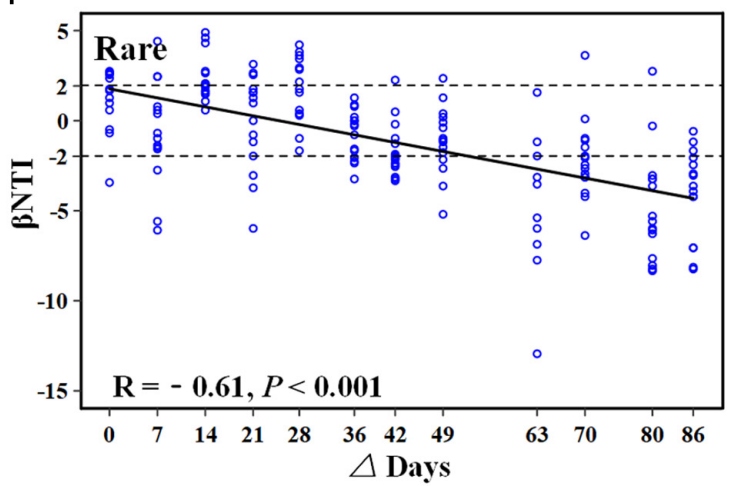

FIGURE 6 | Relationship between $\beta N T I$ values of bacterial community over shrimp ontogeny. The horizontal dashed lines indicate the $\beta N T I$ values of -2 and +2 . An individual community below or above the two dashed lines indicates that determinism dominantly governs the community assembly, while between the two dashed lines indicates that stochasticity is dominant. The relationship between $\beta N T I$ and differences in days gut microbiota (A-C) and bacterioplankton community (D-F) was fitted using linear regression.

\section{Succession Pattern Between Bacterioplankton Community and Shrimp Gut Community}

The diversity of shrimp gut microbiota was relatively stable, whereas the surrounding bacterioplankton diversity increased linearly during shrimp farming. Additionally, the diversity in gut microbiota was generally lower than that in corresponding bacterioplankton community (Supplementary Figure 1), in accordant with the notion that hosts select a subset of surrounding taxa that colonize into their gut (Zoqratt et al., 2018). In contrast, the linearly increased diversity of bacterioplankton could be attributed to the accumulation of nutritional sources along shrimp farming (Supplementary Figure 2), leading to the diversification of microbes. Both the shrimp gut microbiota and bacterioplankton community exhibited sequential changes over shrimp ontogeny (Figure 1). Consistently, there is ample evidence that the gut microbiota is primarily affected by host age in diverse aquatic animals (Burns et al., 2016; Yan et al., 2016). Given the sequential changes in both the gut microbiota and bacterioplankton communities (Figure 1), we compared temporal turnover rate of the two communities. Bacterioplankton community exhibited significantly steeper turnover (more rapid deviation from original 
to new state) than gut microbiota (Figure 2), indicating that host-associated communities are more temporally stable than free-living counterparts. This finding was further supported by the MRM model, revealing that the succession of gut microbiota $\left(R^{2}=0.21\right)$ were less explained by the shrimp age, compared with that of bacterioplankton community $\left(R^{2}=0.66\right)$ (Table 2). It seems that host gut offers a relatively stable microenvironment for commensals. Consistent with this assertion, it has been shown that fish gut is a more suitable environment than external skin mucus (Sylvain et al., 2020). In other words, gut microbiota experiences regular incremental shifts such as the maturity of physiology and immunity over shrimp ontogeny. Additionally, the rapid succession of bacterioplankton community could be attributed to temporally varied water geochemical variables during shrimp farming (Supplementary Figure 2), instead of direct role of shrimp age itself (see details in Figure 3), although we have tried to minimize colinearity among environmental factors. Indeed, the important role of shrimp age in governing both communities did not completely rule out the effects of other factors. We also detected that water temperature and $\mathrm{pH}$ strongly affected the temporal successions of total and abundant bacterial communities in both habitats but not the rare subcommunities (Table 2). Water temperature and $\mathrm{pH}$ have been extensively observed as key factors in shaping bacterioplankton community (Luo et al., 2019; Nyirabuhoro et al., 2019). Interestingly, shrimp are poikilotherms, while their gut microbiotas are sensitive to changes in rearing water temperature $\left(23.8-30.7^{\circ} \mathrm{C}\right)$ (Supplementary Figure 2). Changes in the environmental temperature of aquaculture water could affect the metabolic and physiological functions of shrimp, thus indirectly alter the gut microbiotas. In accordance, it has been shown that water temperature affects feeding, growth, and survival of Litopenaeus vannaei. Rearing water temperature was positively associated with the abundances of anaerobes and the anaerobic Bifidobacterium ( $\mathrm{Li}$ et al., 2018). Considering the functional importance of gut microbiota in host health, this pattern may partially explain why a sudden change in water temperature generally causes shrimp disease (Estrada-Perez et al., 2020). Furthermore, water temperature could directly alter the bacterioplankton community (Yang et al., 2018), which in turn affects shrimp gut microbiota. It is worthy to emphasize that lifestyle is also key factor in shaping the gut microbiota of shrimp (Cornejo-Granados et al., 2018). More specifically, there are distinct gut microbiotas between wild and aquacultured shrimp (Cornejo-Granados et al., 2017), low- and high-salinity-cultured shrimp (Hou et al., 2020), and freshwater and marine conditions (Cornejo-Granados et al., 2018). In this regard, follow-up investigations following a spatial sampling strategy is needed to test whether the pattern observed here is shared between culture ecosystems or ecosystem dependent.

\section{Interplay Among Geochemical Factor, Bacterioplankton Community, and Gut Microbiota Over Shrimp Ontogeny}

SEM uncovered that rearing water salinity, $\mathrm{pH}, \mathrm{TP}$, and DO were the key determinants in driving the succession of bacterioplankton communities (Figure 3), corroborating recent studies obtained in shrimp, crab, and tilapia aquaculture conditions (Giatsis et al., 2015; Yang et al., 2018; Dai et al., 2020; Hou et al., 2020). Water DO, pH, and salinity directly affected the structures of bacterioplankton community (Figure 3), in accordance with the notion that bacterioplankton communities are extremely sensitive to subtle environmental changes (Or et al., 2012; Yang et al., 2018). In aquaculture ecosystem, the level of water phosphorus is usually low, thus bacterioplankton communities often experience P-unsaturation (Duhamel et al., 2021). Accordingly, the concentration of TP was significantly and positively correlated with the structures of bacterioplankton community (Liu et al., 2019). However, we found that a sharp increase in TP at the later farming stage exerted a negative effect on bacterioplankton communities (Figure 3 and Supplementary Figure 2). In contrast, there were negligible and insignificant effects of water salinity, $\mathrm{pH}, \mathrm{TP}$, and DO on the gut microbiota (Figure 3 and Supplementary Table 3). A possible explanation for this pattern is that host could buffer external environmental change. As a result, the gut microbiota is less affected by water geochemical factors. Bacterioplankton community only exerted a weak direct effect on the gut microbiota, compared with shrimp age (Figure 3). Consistently, ample evidence has shown that the gut microbiota in aquatic animals is distinct from surrounding environments (Zhang et al., 2018, 2021; Xiong et al., 2019b). It has been proposed that hosts selectively filter particular bacteria from the rearing environments, rather than randomly ingesting surrounding taxa (Stephens et al., 2016; Yan et al., 2016). In accordance, shrimp age (a proxy of gut maturity) is the main biological variable governing the succession of gut microbiota (Figures 2, 3 and Table 2). Together, changes in the geochemical variables strongly affect the structures of bacterioplankton community during shrimp farming, whereas the gut microbiota does not simply mirror the rearing bacterioplankton community.

\section{Shrimp Gut Commensals Sourced From Their Larvae}

Although shrimp live in rearing water, relative abundances of the top 20 bacterial genera in shrimp gut were insignificantly associated (12 in 20 cases) with those in bacterioplankton community (Figure 4). For example, Vibrio genus was predominant in shrimp gut but was rare in rearing water. This is consistent with previous studies showing that the dominant genera are distinct between shrimp gut and rearing water and sediment (Zhou et al., 2021). Vibrio and Photobacterium members are long known to be opportunistic pathogens in shrimp aquaculture (Manilal et al., 2010). Nevertheless, the majority of vibrios are not pathogenic, many are commensal or even beneficial, including the carbon cycle and osmoregulation (Johnson, 2013). Indeed, Vibrio species have been frequently detected as a dominant population in shrimp gut (Chaiyapechara et al., 2012). In accordance, a few vibrio strains, e.g., Vibrio alginolyticus UTM 102, have been applied as probiotics in shrimp aquaculture (Balcázar et al., 2007). Similarly, Photobacterium strains are common in the intestinal contents of marine animals (Chaiyapechara et al., 2012). In addition, Ruegeria, Marivita, 
and Flavobacterium harbor the specific ability in degrading organic matter (Williams et al., 2012; Sun et al., 2019; Huang et al., 2020), which were enriched at the late stage of aquaculture water (Figure 4). The relative abundance of Pseudoalteromonas in shrimp gut was negatively associated with that in rearing water (Figure 4). Consistently, Pseudoalteromonas strains have been successfully used as probiotics in shrimp farming. In these regard, shrimp could select some beneficial commensals that improve their fitness.

Furthermore, we evaluated the contribution of internal sources (gut commensals of younger host) on the shrimp gut microbiota. Theoretically, aquatic animals are born without microorganisms, thus their gut commensals should source from the surrounding environments after birth (Yan et al., 2016). However, the majority of gut commensals of shrimp gut microbiota sourced from their younger host, rather than bacterioplankton communities (Figure 5), which reinforces the importance of the gut microbiome in younger host (Kerr et al., 2015). Similarly, it has been shown that shrimp acquires a small proportion of commensals from rearing water over development (Xiong et al., 2019b). The contribution of surrounding bacterioplankton communities on gut commensals markedly varied over shrimp ontogeny (Figure 5). We propose several explanations for this pattern. According to the coevolution hypothesis (McFall-Ngai et al., 2013), it is mandatory for larva to recruit suitable taxa that expand the range of diet digestion due to incomplete digestive system. Thus, to improve hosts' fitness, the colonization of gut commensals is filtered from rearing species pool as a result of deterministic processes. However, as host matures, the initial "winners" could be reassembled, thereby resulting in host stage-specific gut microbiota (Stephens et al., 2016; Yan et al., 2016). Additionally, temporal dynamics of environmental variables directly alter the bacterioplankton communities (Figure 4), leading to nonlinear contribution of bacterioplankton communities to gut microbiota along shrimp farming. The skewed source pattern on day 56 could be induced by sudden increase in TP content and the low level of DO (Figure 2). In accordance, the SEM uncovered that water TP and DO exerted indirect effects on the gut microbiota (Supplementary Table 3). However, there were still a high proportion of "unknown" sources (Figure 5), which could be attributed to the uncollected species pools, e.g., diet, air and farmer. Together, gut commensals primarily source from adjacent younger shrimp. In this regard, we propose the isolation of probiotics from larval gut, which could be persist over shrimp ontogeny.

\section{Ecological Processes Governing the Assembly of Bacterial Community}

Bacterioplankton communities are more closely phylogenetically clustered than the gut microbiotas, as supported by significantly lower mean value of ses.MNTD (Supplementary Figure 4), as observed in the present study and elsewhere (Xiong et al., $2019 b)$. In addition, the $\beta$ NTI values of gut microbiota and bacterioplankton community divergently changed during shrimp farming (Figures 6A,B), though both communities exhibited sequential shifts in the community structure (Figures 1, 2). The gut microbiota tended to be governed by variable selection ( $\beta$ NTI values $>2$ ), while the bacterioplankton community was affected by homogeneous selection $(\beta$ NTI values $<-2$ ) (Figures 6A,B). The logic behind this may be that shrimp has not reached full maturity, though we collected samples over an entire shrimp farming (Lucas et al., 2010). Consistent with this assertion, the gut microbiota significantly changed between every paired sampling (Supplementary Table 1). Similarly, it has been shown that the succession of shrimp gut microbiota is more driven by species replacement than bacterioplankton community (Xiong et al., 2019b). In contrast, geochemical variables of rearing water were relatively stable at the later farming days (Supplementary Figure 2), thus bacterioplankton communities were governed by homogeneous selection. Accordingly, the structures of bacterioplankton community were comparable between some adjacent pairs (Supplementary Table 2). Thus, host-associated and free-living bacterial communities are governed by different ecological processes. Considering the functional importance of gut microbiota in host health, additional works are required to explore the underlying ecological processes in governing the overlooked host-associated microbes. Notably, rare subcommunities in both the gut and rearing water were affected by homogeneous selection (Figures 6E,F), whereas their abundant counterparts were shaped by random processes (Figures 6C,D). Rare members serve as "seed bank" in a given community, which could switch to abundant taxa in response to changing environments (Magurran and Henderson, 2003). That is, rare taxa adapt to specific conditions that are strongly selected by external factors. In accordance, rare subcommunities were governed by deterministic processes (Figure 6). Corroborating recent works, rare subcommunity shown to be dominated by deterministic processes, while abundant subcommunity is influenced largely by stochastic processes in agricultural soils (Jiao and Lu, 2020) and freshwater ecosystems (Liu et al., 2015). The broad fitness of abundant taxa facilitates their successive establishment across a wide range of environmental conditions (Wan et al., 2021), e.g., variations in host maturity and geochemical factors here. By this logic, the abundant subcommunities are less affected by local variables, leading to the predominance of stochasticity (Figure 6). That is, no phylogenetic signs were detected for abundant communities. Consistently, there is ample evidence that rare taxa exhibit greater sensitivity to environmental factors than abundant species (Mo et al., 2018). Under these scenarios, it seems that the rare subcommunities are governed by deterministic processes, while the assembly of their abundant counterparts was stochastic across habitats, such as host gut and rearing water here.

\section{CONCLUSION}

Host-associated bacterial community is more temporally stable than their free-living counterpart, as supported by the significant lower temporal turnover rate. In accordance, the gut microbiota is less affected by the rearing water geochemical variables, compared with bacterioplankton community. Intriguingly, the shrimp gut microbiota does not simply mirror the rearing bacterioplankton communities. Instead, gut commensals mainly 
inherit from their younger shrimp, rather than the rearing water. It seems that host-associated and free-living microbes are assembled by divergently ecological processes. That is, the gut microbiota is governed by variable selection over shrimp ontogeny, while the rearing bacterioplankton community is shaped by homogeneous selection. However, the determinism of rare and stochasticity of abundant subcommunities are consistent between shrimp gut and rearing water. These findings greatly broaden our understanding on the underlying ecological processes governing the temporal successions of host-associated and free-living microbial communities.

\section{DATA AVAILABILITY STATEMENT}

Raw sequence data are available in the BIG Data Center, Chinese Academy of Sciences, under code CRA004710 at http://bigd.big. ac.cn/gsa.

\section{ETHICS STATEMENT}

The animal study was reviewed and approved by the Guide for the Care and Use of Laboratory Animals of Ningbo University.

\section{REFERENCES}

Anderson, M. J. (2010). A new method for non-parametric multivariate analysis of variance. Aust. Ecol. 26, 32-46. doi: 10.1046/j.1442-9993.2001.0 1070.x

AQSIQ (2007). The Specification for Marine Monitoring of China-Part 4: Seawater Analysis (GB 17378.4e2007). General Administration of Quality Supervision, Inspection and Quarantine (AQSIQ) of the People's Republic of China. Beijing: China Standard Press (in Chinese).

Balcázar, J. L., Rojas-Luna, T., and Cunningham, D. P. (2007). Effect of the addition of four potential probiotic strains on the survival of pacific white shrimp (Litopenaeus vannamei) following immersion challenge with Vibrio parahaemolyticus. J. Invertebr. Pathol. 96, 147-150. doi: 10.1016/j.jip.2007.04. 008

Baselga, A. (2010). Partitioning the turnover and nestedness components of beta diversity. Global Ecol. Biogeogr. 19, 134-143. doi: 10.1111/j.1466-8238.2009. 00490.x

Brown, M. V., Ostrowski, M., Grzymski, J. J., and Lauro, F. M. (2014). A trait based perspective on the biogeography of common and abundant marine bacterioplankton clades. Mar. Genomics 15, 17-28. doi: 10.1016/j.margen.2014. 03.002

Burns, A. R., Stephens, W. Z., Stagaman, K., Wong, S., Rawls, J. F., Guillemin, K., et al. (2016). Contribution of neutral processes to the assembly of gut microbial communities in the zebrafish over host development. ISME J. 10, 655-664. doi: 10.1038/ismej.2015.142

Byrne, B. M. (2001). Structural Equation Modeling with AMOS. Basic Concepts Applications \& Programming. Mahwah NJ: Lawrence Erlbaum Associates Publishers.

Caporaso, J. G., Kuczynski, J., Stombaugh, J., Bittinger, K., Bushman, F. D., Costello, E. K., et al. (2010). QIIME allows analysis of high-throughput community sequencing data. Nat. Methods 7, 335-336. doi: 10.1038/nmeth.f. 303

Chaiyapechara, S., Rungrassamee, W., Suriyachay, I., Kuncharin, Y., Klanchui, A., Karoonuthaisiri, N., et al. (2012). Bacterial community associated with the intestinal tract of P. Monodon in commercial farms. Microb. Ecol. 63, 938-953. doi: 10.1007/s00248-011-9936-2

\section{AUTHOR CONTRIBUTIONS}

JC and JX conceived and designed the research. WZ, ZZ, and QQ conducted the experiments. JX contributed analytical tools. JX and $\mathrm{WZ}$ analyzed the data. WZ wrote the manuscript with help from JX and ZZ. All authors read and approved the manuscript.

\section{FUNDING}

This work was financially supported by the Natural Science Fund for Distinguished Young Scholars of Zhejiang Province (LR19C030001), the National Natural Science Foundation of China (31872693 and 32071549), the Key Public Welfare Technology Application Research Project of Ningbo (202002N3032), and the K.C. Wong Magna Fund in Ningbo University.

\section{SUPPLEMENTARY MATERIAL}

The Supplementary Material for this article can be found online at: https://www.frontiersin.org/articles/10.3389/fmicb. 2021.752750/full\#supplementary-material

Chase, J. M. (2010). Stochastic community assembly causes higher biodiversity in more productive environments. Science 328, 1388-1391. doi: 10.1126/science. 1187820

Cornejo-Granados, F., Gallardo-Becerra, L., Leonardo-Reza, M., Ochoa-Romo, J. P., and Ochoa-Leyva, A. (2018). A meta-analysis reveals the environmental and host factors shaping the structure and function of the shrimp microbiota. PeerJ 6:e5382. doi: 10.7717/peerj.5382

Cornejo-Granados, F., Lopez-Zavala, A. A., Gallardo-Becerra, L., Mendoza-Vargas, A., Sánchez, F., Vichido, R., et al. (2017). Microbiome of Pacific Whiteleg shrimp reveals differential bacterial community composition between wild, aquacultured and AHPND/EMS outbreak conditions. Sci. Rep. 7:11783. doi: 10.1038/s41598-017-11805-w

Dai, W., Xiong, J., Zheng, H., Ni, S., Ye, Y., and Wang, C. (2020). Effect of Rhizophora apiculata plantation for improving water quality, growth, and health of mud crab. Appl. Microbiol. Biotech. 104, 6813-6824. doi: 10.1007/ s00253-020-10716-7

De Schryver, P., Defoirdt, T., Sorgeloos, P., and Rall, G. F. (2014). Early mortality syndrome outbreaks: a microbial management issue in shrimp farming? PLoS Pathog. 10:e1003919. doi: 10.1371/journal.ppat.1003919

DeSantis, T. Z., Hugenholtz, P., Larsen, N., Rojas, M., Brodie, E. L., Keller, K., et al. (2006). Greengenes, a chimera-checked 16S rRNA gene database and workbench compatible with ARB. Appl. Environ. Microbiol. 72, 5069-5072. doi: 10.1128/AEM.03006-05

Duhamel, S., Diaz, J. M., Adams, J. C., Djaoudi, K., Steck, V., and Waggoner, E. M. (2021). Phosphorus as an integral component of global marine biogeochemistry. Nat. Geosci. 14, 359-368. doi: 10.1038/s41561-021-00755-8

Edgar, R. C. (2010). Search and clustering orders of magnitude faster than BLAST. Bioinformatics 26, 2460-2461. doi: 10.1093/bioinformatics/btq461

Estrada-Perez, N., Ruiz-Velazco, J. M., Magallon-Barajas, F. J., Campa-Cordova, A. I., and Hernández-Llamas, A. (2020). Dynamic stock model for analysing semi-intensive production of whiteleg shrimp Litopenaeus (Penaeus) vannamei affected by the acute hepatopancreatic necrosis disease: assessment of disease severity indicators and relationships with pond water quality parameters. Aquac. Res. 51, 242-254. doi: 10.1111/are.14370

García-López, R., Cornejo-Granados, F., Lopez-Zavala, A. A., Cota-Huízar, A., and Ochoa-Leyva, A. (2021). OTUs and ASVs produce comparable taxonomic and 
diversity from shrimp microbiota $16 \mathrm{~S}$ profiles using tailored abundance filters. Genes 12:564. doi: 10.3390/genes12040564

Giatsis, C., Sipkema, D., Smidt, H., Heilig, H., Benvenuti, G., Verreth, J., et al. (2015). The impact of rearing environment on the development of gut microbiota in tilapia larvae. Sci. Rep. 5:18206. doi: 10.1038/srep18206

Glassman, S. S., and Martiny, J. B. H. (2018). Broadscale ecological patterns are robust to use of exact sequence variants versus operational taxonomic units. mSphere 3:e00148-18. doi: 10.1128/mSphere.00148-18

Goslee, S. C., and Urban, D. L. (2007). The ecodist package for dissimilarity-based analysis of ecological data. J. Statal. Softw. 22, 1-19. doi: 10.18637/jss.v022.i07

Hou, D., Huang, Z., Zeng, S., Liu, J., Wei, D., Deng, X., et al. (2018). Intestinal bacterial signatures of white feces syndrome in shrimp. Appl. Microbiol. Biotech. 102, 3701-3709. doi: 10.1007/s00253-018-8855-2

Hou, D., Zhou, R., Zeng, S., Wei, D., Deng, X., Xing, C., et al. (2020). Intestine bacterial community composition of shrimp varies under low-and high-salinity culture conditions. Front. Microbiol. 11:2765. doi: 10.3389/fmicb.2020.589164

Huang, F., Pan, L., Song, M., Tian, C., and Gao, S. (2018). Microbiota assemblages of water, sediment, and intestine and their associations with environmental factors and shrimp physiological health. Appl. Microbiol. Biotech. 102, 85858598. doi: 10.1007/s00253-018-9229-5

Huang, L., Guo, H., Chen, C., Huang, X., Chen, W., Bao, F., et al. (2020). The bacteria from large-sized bioflocs are more associated with the shrimp gut microbiota in culture system. Aquaculture 523:735159. doi: 10.1016/j. aquaculture.2020.735159

Jiao, S., and Lu, Y. (2020). Soil $\mathrm{pH}$ and temperature regulate assembly processes of abundant and rare bacterial communities in agricultural ecosystems. Environ. Microbiol. 22, 1052-1065. doi: 10.1111/1462-2920.14815

Johnson, C. N. (2013). Fitness factors in vibrios: a mini-review. Microb. Ecol. 65, 826-851. doi: 10.1007/s00248-012-0168-x

Kembel, S. W., Cowan, P. D., Helmus, M. R., Cornwell, W. K., Morlon, H., Ackerly, D. D., et al. (2010). Picante: R tools for integrating phylogenies and ecology. Bioinformatics 26, 1463-1464. doi: 10.1093/bioinformatics/btq166

Kerr, C. A., Grice, D. M., Tran, C. D., Bauer, D. C., Li, D., Hendry, P., et al. (2015). Early life events influence whole-of-life metabolic health via gut microflora and gut permeability. Crit. Rev. Microbiol. 41, 326-340. doi: 10.3109/1040841X. 2013.837863

Knights, D., Kuczynski, J., Charlson, E. S., Zaneveld, J., Mozer, M. C., Collman, R. G., et al. (2011). Bayesian community-wide culture-independent microbial source tracking. Nat. Methods 8, 761-763. doi: 10.1038/nmeth.1650

Legendre, P., Lapointe, F. J., and Casgrain, P. (1994). Modeling brain evolution from behavior: a permutational regression approach. Evolution 48, 1487-1499. doi: 10.1111/j.1558-5646.1994.tb02191.x

Li, E., Xu, C., Wang, X., Wang, S., Zhao, Q., Zhang, M., et al. (2018). Gut microbiota and its modulation for healthy farming of Pacific white shrimp Litopenaeus vannamei. Rev. Fish. Sci. Aquac. 26, 381-399. doi: 10.1080/23308249.2018. 1440530

Lichstein, J. W. (2007). Multiple regression on distance matrices: a multivariate spatial analysis tool. Plant Ecol. 188, 117-131. doi: 10.1007/s11258-006-9126-3

Liu, L., Chen, H., Liu, M., Yang, J. R., Xiao, P., Wilkinson, D. M., et al. (2019). Response of the eukaryotic plankton community to the cyanobacterial biomass cycle over 6 years in two subtropical reservoirs. ISME J. 13, 2196-2208. doi: 10.1038/s41396-019-0417-9

Liu, L., Yang, J., Yu, Z., and Wilkinson, D. M. (2015). The biogeography of abundant and rare bacterioplankton in the lakes and reservoirs of China. ISME J. 9, 2068-2077. doi: 10.1038/ismej.2015.29

Logares, R., Audic, S., Bass, D., Bittner, L., Boutte, C., Christen, R., et al. (2014). Patterns of rare and abundant marine microbial eukaryotes. Curr. Biol. 24, 813-821. doi: 10.1016/j.cub.2014.02.050

Lu, J., Li, X., Qiu, Q., Chen, J., and Xiong, J. (2022). Gut interkingdom predator-prey interactions are key determinants of shrimp health. Aquaculture 546:737304. doi: 10.1016/j.aquaculture.2021.737304

Lucas, R., Courties, C., Herbland, A., Goulletquer, P., Marteau, A. L., and Lemonnier, H. (2010). Eutrophication in a tropical pond: understanding the bacterioplankton and phytoplankton dynamics during a vibriosis outbreak using flow cytometric analyses. Aquaculture 310, 112-121.

Luo, Z., Li, S., Hou, K., and Ji, G. (2019). Spatial and seasonal bacterioplankton community dynamics in the main channel of the Middle Route of South-toNorth water diversion project. Res. Microbiol. 170, 24-34.
Lynch, M. D., and Neufeld, J. D. (2015). Ecology and exploration of the rare biosphere. Nat. Rev. Microbiol. 13, 217-229.

Magurran, A. E., and Henderson, P. A. (2003). Explaining the excess of rare species in natural species abundance distributions. Nature 422, 714-716.

Manilal, A., Sujith, S., Selvin, J., Shakir, C., Gandhimathi, R., and Kiran, G. S. (2010). Virulence of vibrios isolated from diseased black tiger shrimp, Penaeus monodon, Fabricius. J. World Aquacult. Soc. 41, 332-343.

McFall-Ngai, M., Hadfield, M. G., Bosch, T. C., Carey, H. V., Domazet-Lošo, T., Douglas, A. E., et al. (2013). Animals in a bacterial world, a new imperative for the life sciences. Proc. Nat. Acad. Sci. U.S.A. 110, 3229-3236.

Mo, Y., Zhang, W., Yang, J., Lin, Y., Yu, Z., and Lin, S. (2018). Biogeographic patterns of abundant and rare bacterioplankton in three subtropical bays resulting from selective and neutral processes. ISME J. 12, 2198-2210.

Nyirabuhoro, P., Liu, M., Xiao, P., Liu, L., Yu, Z., Wang, L., et al. (2019). Seasonal variability of conditionally rare taxa in the water column bacterioplankton community of subtropical reservoirs in China. Microb. Ecol. 80, 14-26.

Or, A., Shtrasler, L., and Gophna, U. (2012). Fine-scale temporal dynamics of a fragmented lotic microbial ecosystem. Sci. Rep. 2:207.

Pester, M., Bittner, N., Deevong, P., Wagner, M., and Loy, A. (2010). A 'rare biosphere'microorganism contributes to sulfate reduction in a peatland. ISME J. 4, 1591-1602. doi: 10.1038/ismej.2010.75

R Core Team (2013). R: A Language and Environment for Statistical Computing. Vienna: The R Foundation for Statistical Computing.

Shade, A., Jones, S., Caporaso, J. G., Handelsman, J., Knight, R., Fierer, N., et al. (2014). Conditionally rare taxa disproportionately contribute to temporal changes in microbial diversity. mBio 5:e01371-14. doi: 10.1128/mBio.01371-14

Song, M., Pan, L., Zhang, M., Huang, F., Gao, S., and Tian, C. (2020). Changes of water, sediment, and intestinal bacterial communities in Penaeus japonicus cultivation and their impacts on shrimp physiological health. Aquac. Int. 28, 1847-1865. doi: 10.1007/s10499-020-00562-9

Stegen, J. C., Lin, X., Konopka, A. E., and Fredrickson, J. K. (2012). Stochastic and deterministic assembly processes in subsurface microbial communities. ISME J. 6, 1653-1664. doi: 10.1038/ismej.2012.22

Stephens, W. Z., Burns, A. R., Stagaman, K., Wong, S., Rawls, J. F., Guillemin, K., et al. (2016). The composition of the zebrafish intestinal microbial community varies across development. ISME J. 10, 644-654. doi: 10.1038/ismej.2015.140

Sun, F., Wang, Y., Wang, C., Zhang, L., Tu, K., and Zheng, Z. (2019). Insights into the intestinal microbiota of several aquatic organisms and association with the surrounding environment. Aquaculture 507, 196-202. doi: 10.1016/ j.aquaculture.2019.04.026

Sylvain, F. -É, Holland, A., Bouslama, S., Audet-Gilbert, É, Lavoie, C., Val, A. L., et al. (2020). Fish skin and gut microbiomes show contrasting signatures of host species and habitat. Appl. Environ. Microbiol. 86:e0789-20. doi: 10.1128/AEM. 00789-20

Talbot, J. M., Bruns, T. D., Taylor, J. W., Smith, D. P., Branco, S., Glassman, S. I., et al. (2014). Endemism and functional convergence across the North American soil mycobiome. Proc. Nat. Acad. Sci. U.S.A. 111:6341.

Van Der Gast, C. J., Ager, D., and Lilley, A. K. (2008). Temporal scaling of bacterial taxa is influenced by both stochastic and deterministic ecological factors. Environ. Microbiol. 10, 1411-1418. doi: 10.1111/j.1462-2920.2007.01550.x

Vanwonterghem, I., Jensen, P. D., Dennis, P. G., Hugenholtz, P., Rabaey, K., and Tyson, G. W. (2014). Deterministic processes guide long-term synchronised population dynamics in replicate anaerobic digesters. ISME J. 8, 2015-2028.

Venkataraman, A., Bassis, C. M., Beck, J. M., Young, V. B., Curtis, J. L., Huffnagle, G. B., et al. (2015). Application of a neutral community model to assess structuring of the human lung microbiome. mBio 6:e02284-14.

Wan, W., Gadd, G. M., Yang, Y., Yuan, W., Gu, J., Ye, L., et al. (2021). Environmental adaptation is stronger for abundant rather than rare microorganisms in wetland soils from the Qinghai-Tibet Plateau. Mol. Ecol. 30, 2390-2403.

Webb, C. O., Ackerly, D. D., and Donoghue, M. P. J. (2002). Phylogenies and community ecology. Ann. Rev. Ecol. Syst. 33, 475-505.

Williams, T. J., Long, E., Evans, F., DeMaere, M. Z., Lauro, F. M., Raftery, M. J., et al. (2012). A metaproteomic assessment of winter and summer bacterioplankton from Antarctic Peninsula coastal surface waters. ISME J. 6, 1883-1900.

Xiao, F., Zhu, W., Yu, Y., He, Z., Wu, B., Wang, C., et al. (2021). Host development overwhelms environmental dispersal in governing the ecological succession of zebrafish gut microbiota. NPJ Biofilms Microbiomes 7:5. 
Xiong, J. (2018). Progress in the gut microbiota in exploring shrimp disease pathogenesis and incidence. Appl. Microbiol. Biotech. 102, 7343-7350.

Xiong, J., Dai, W., and Li, C. (2016). Advances, challenges, and directions in shrimp disease control: the guidelines from an ecological perspective. Appl. Microbiol. Biotech. 100, 6947-6954.

Xiong, J., Dai, W., Qiu, Q., Zhu, J., Yang, W., and Li, C. (2018). Response of host-bacterial colonization in shrimp to developmental stage, environment and disease. Mol. Ecol. 27, 3686-3699.

Xiong, J., Xuan, L., Yu, W., Zhu, J., Qiu, Q., and Chen, J. (2019b). Spatiotemporal successions of shrimp gut microbial colonization: high consistency despite distinct species pool. Environ. Microbiol. 21, 1383-1394.

Xiong, J., Nie, L., and Chen, J. (2019a). Current understanding on the roles of gut microbiota in fish disease and immunity. Zool. Res. 40, 70-76.

Xiong, J., Wang, K., Wu, J., Qiuqian, L., Yang, K., Qian, Y., et al. (2015). Changes in intestinal bacterial communities are closely associated with shrimp disease severity. Appl. Microbiol. Biotech. 99, 6911-6919.

Xiong, J., Zhu, J., Dai, W., Dong, C., Qiu, Q., and Li, C. (2017). Integrating gut microbiota immaturity and disease-discriminatory taxa to diagnose the initiation and severity of shrimp disease. Environ. Microbiol. 19, 1490-1501.

Xiong, J., Zhu, J., Wang, K., Wang, X., Ye, X., Liu, L., et al. (2014). The temporal scaling of bacterioplankton composition: high turnover and predictability during shrimp cultivation. Microb. Ecol. 67, 256-264.

Yan, Q., Li, J., Yu, Y., Wang, J., He, Z., Van Nostrand, J. D., et al. (2016). Environmental filtering decreases with fish development for the assembly of gut microbiota. Environ. Microbiol. 18, 4739-4754.

Yang, W., Zheng, C., Zheng, Z., Wei, Y., Lu, K., and Zhu, J. (2018). Nutrient enrichment during shrimp cultivation alters bacterioplankton assemblies and destroys community stability. Ecotoxicol. Environ. Saf. 156, 366-374.

Zhang, D., Wang, X., Xiong, J., Zhu, J., Wang, Y., Zhao, Q., et al. (2014). Bacterioplankton assemblages as biological indicators of shrimp health status. Ecol. Indic. 38, 218-224.

Zhang, X., Li, X., Lu, J., Qiu, Q., Chen, J., and Xiong, J. (2021). Quantifying the importance of external and internal sources to the gut microbiota in juvenile and adult shrimp. Aquaculture 531:735910.
Zhang, Z., Li, D., Refaey, M. M., Xu, W., Tang, R., and Li, L. (2018). Host age affects the development of southern catfish gut bacterial community divergent from that in the food and rearing water. Front. Microbiol. 9:495. doi: 10.3389/fmicb. 2018.00495

Zhou, J., and Ning, D. (2017). Stochastic community assembly: does it matter in microbial ecology? Microbiol. Mol. Biol. Rev. 81:e00002-17.

Zhou, J., Deng, Y., Zhang, P., Xue, K., Liang, Y., Van Nostrand, J. D., et al. (2014). Stochasticity, succession, and environmental perturbations in a fluidic ecosystem. Proc. Nat. Acad. Sci. U.S.A. 111, 836-845.

Zhou, L., Qu, Y., Qin, J. G., Chen, L., Han, F., and Li, E. (2021). Deep insight into bacterial community characterization and relationship in the pond water, sediment and the gut of shrimp (Penaeus japonicus). Aquaculture 539:736658. doi: 10.1016/j.aquaculture.2021.736658

Zoqratt, M. Z. H. M., Eng, W. W. H., Thai, B. T., Austin, C. M., and Gan, H. M. (2018). Microbiome analysis of Pacific white shrimp gut and rearing water from Malaysia and Vietnam: implications for aquaculture research and management. PeerJ 6:e5826.

Conflict of Interest: The authors declare that the research was conducted in the absence of any commercial or financial relationships that could be construed as a potential conflict of interest.

Publisher's Note: All claims expressed in this article are solely those of the authors and do not necessarily represent those of their affiliated organizations, or those of the publisher, the editors and the reviewers. Any product that may be evaluated in this article, or claim that may be made by its manufacturer, is not guaranteed or endorsed by the publisher.

Copyright $\odot 2021$ Zhang, Zhu, Chen, Qiu and Xiong. This is an open-access article distributed under the terms of the Creative Commons Attribution License (CC BY). The use, distribution or reproduction in other forums is permitted, provided the original author(s) and the copyright owner(s) are credited and that the original publication in this journal is cited, in accordance with accepted academic practice. No use, distribution or reproduction is permitted which does not comply with these terms. 